\title{
Mercury Exposure in Association With Decrease of Liver Function in Adults: A Longitudinal Study
}

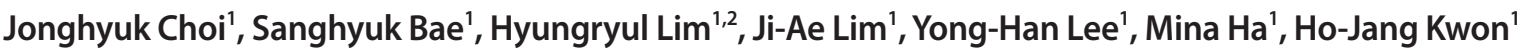 \\ ${ }^{1}$ Department of Preventive Medicine, Dankook University College of Medicine, Cheonan; ${ }^{2}$ Republic of Korea Army Headquarters, Gyeryong, Korea
}

Objectives: Although mercury $(\mathrm{Hg})$ exposure is known to be neurotoxic in humans, its effects on liver function have been less often reported. The aim of this study was to investigate whether total $\mathrm{Hg}$ exposure in Korean adults was associated with elevated serum levels of the liver enzymes aspartate aminotransferase (AST), alanine transaminase (ALT), and gamma-glutamyltransferase (GGT).

Methods: We repeatedly examined the levels of total $\mathrm{Hg}$ and liver enzymes in the blood of 508 adults during 2010-2011 and 20142015. Cross-sectional associations between levels of blood $\mathrm{Hg}$ and liver enzymes were analyzed using a generalized linear model, and nonlinear relationships were analyzed using a generalized additive mixed model. Generalized estimating equations were applied to examine longitudinal associations, considering the correlations of individuals measured repeatedly.

Results: GGT increased by $11.0 \%$ (95\% confidence interval $[\mathrm{Cl}], 4.5$ to $18.0 \%$ ) in women and $8.1 \%(95 \% \mathrm{Cl},-0.5$ to $17.4 \%)$ in men per doubling of Hg levels, but AST and ALT were not significantly associated with $\mathrm{Hg}$ in either men or women. In women who drank more than 2 or 3 times per week, AST, ALT, and GGT levels increased by $10.6 \%(95 \% \mathrm{Cl}, 4.2$ to $17.5 \%), 7.7 \%(95 \% \mathrm{Cl}, 1.1$ to $14.7 \%)$, and $37.5 \%$ $(95 \% \mathrm{Cl}, 15.2$ to $64.3 \%)$ per doubling of $\mathrm{Hg}$ levels, respectively, showing an interaction between blood $\mathrm{Hg}$ levels and drinking.

Conclusions: $\mathrm{Hg}$ exposure was associated with an elevated serum concentration of GGT. Especially in women who were frequent drinkers, AST, ALT, and GGT showed a significant increase, with a significant synergistic effect of $\mathrm{Hg}$ and alcohol consumption.

Key words: Mercury, Aspartate aminotransferases, Alanine transaminase, Gamma-glutamyltransferase, Interaction

\section{INTRODUCTION}

Mercury $(\mathrm{Hg})$ exists naturally as elemental $\mathrm{Hg}$, in inorganic mercurous and mercuric compounds, and in organic $\mathrm{Hg}$ compounds. These 3 types of $\mathrm{Hg}$ are known to have different toxicity

Received: July 1, 2017 Accepted: October 24, 2017

Corresponding author: Mina $\mathrm{Ha}, \mathrm{MD}, \mathrm{PhD}$

119 Dandae-ro, Dongnam-gu, Cheonan 31116, Korea

Tel: +82-41-550-3854, Fax: +82-41-556-6461

E-mail: minaha@dku.edu

This is an Open Access article distributed under the terms of the Creative Commons Attribution Non-Commercial License (http://creativecommons.org/licenses/by$\mathrm{nc} / 4.0 / /$ which permits unrestricted non-commercial use, distribution, and reproduction in any medium, provided the original work is properly cited. and health effects [1,2]. Elemental and inorganic forms of $\mathrm{Hg}$ are predominantly absorbed through the respiratory tract, while organic $\mathrm{Hg}$ is mainly absorbed and bioaccumulated through the gastrointestinal tract because of its highly lipophilic nature [1]. $\mathrm{Hg}$ is removed from the human body through urine or feces, and the half-life of total $\mathrm{Hg}$ in the blood was found to be 57 days on average in a Japanese study [3].

In the 2011-2012 National Health and Nutrition Examination Survey (NHANES) data, the geometric mean (95\% confidence interval [CI]) of blood $\mathrm{Hg}$ concentrations in Asians was 1.93 $\mu \mathrm{g} / \mathrm{L}(1.65$ to $2.27 \mu \mathrm{g} / \mathrm{L})$, which was the highest of all the races [4]. In the same study, levels of $2.58 \mu \mathrm{g} / \mathrm{L}$ were found in Chinese participants, $1.29 \mu \mathrm{g} / \mathrm{L}$ in Indians, and $2.48 \mu \mathrm{g} / \mathrm{L}$ in other 
Asian subgroups [4]. However, the geometric mean (95\% Cl) of blood $\mathrm{Hg}$ concentrations in the 2012 and 2015 Korean National Environmental Health Survey (KoNEHS) were $3.08 \mu \mathrm{g} / \mathrm{L}$ ( 2.96 to $3.21 \mu \mathrm{g} / \mathrm{L}$ ) and $3.11 \mu \mathrm{g} / \mathrm{L}$ (3.02 to $3.21 \mu \mathrm{g} / \mathrm{L}$ ), respectively, which were higher than the NHANES findings for Asians in 2011-2012. In the 2011 Korea National Health and Nutrition Examination Survey (KNHANES), the corresponding level was $3.08 \mu \mathrm{g} / \mathrm{L}$ (2.95 to $3.22 \mu \mathrm{g} / \mathrm{L})$, which was lower than that of the KoNEHS in 2015, but also higher than the level of the Asians analyzed in the NHANES [5].

The toxicity of high-level $\mathrm{Hg}$ exposure is well known from Minamata disease in Japan, outbreaks of which occurred in 1956 and 1965 due to the consumption of Hg-contaminated seafood [6]. In addition to neurological toxicity, high levels of $\mathrm{Hg}$ exposure affect various human organs, including the cardiovascular, endocrine, reproductive, and immune systems [7]. The mechanisms of its toxicity have been suggested to involve degeneration, oxidative stress, and changes in the energy metabolism of the cell, but are not fully understood [8]. The liver plays a major role in metabolism and detoxification, and $\mathrm{Hg}$ is thought to have structural and functional effects on the liver, but studies of the effects of $\mathrm{Hg}$ exposure on human liver tissue, particularly at relatively low levels, are limited.

Previous epidemiological studies of the effects of $\mathrm{Hg}$ exposure on human liver function have shown inconsistent results. A previous epidemiological study showed that the Minamata area, despite being contaminated with methylmercury, did not have a higher prevalence of liver disease than other areas [9]. In a study of 320 adolescents, no significant associations were found between blood $\mathrm{Hg}$ levels and aspartate aminotransferase (AST) or alanine transaminase (ALT) levels [10]. Other epidemiological studies in adults and the elderly showed a significant positive association between $\mathrm{Hg}$ and AST, ALT, and gamma-glutamyltransferase (GGT) [11-14].

Previous epidemiological studies have mostly analyzed cross-sectional data [10-12,14] and did not consider fish consumption as a potential confounder, although fish are a major source of $\mathrm{Hg}$ exposure $[10,11,13,14]$. In addition, no studies have examined the possibility of a nonlinear relationship between blood $\mathrm{Hg}$ and liver function indices, or the possible role of gender. Therefore, this study aimed to examine associations between total blood $\mathrm{Hg}$ concentration and levels of AST, ALT, and GGT, known risk factors for reduced liver function and non-alcoholic fatty liver disease, with stratification by gender.

\section{METHODS}

\section{Study Population}

The study participants were a subgroup of 2118 adults aged $\geq 19$ years from the Korean Research Project on the Integrated Exposure Assessment of Hazardous Substances for Food Safety cohort recruited nationwide from June 3, 2010 to July 28, 2011. Subjects were sampled by a probability method based on household units stratified by 15 metropolises and provinces (Seoul, Gwangju, Busan, Incheon, Daegu, Daejeon, Ulsan, Gyeonggi, Gangwon, Chungbuk, Chungnam, Jeonbuk, Jeonnam, Gyeongbuk, and Gyeongnam), gender, age, and the sample size was allocated by the square root method [15].

Of the 2118 participants $\geq 19$ years old in the baseline survey, 514 were followed up from October 2, 2014 to September 12,2015 . The follow-up was carried out in 3 sequential steps: mailing a notice, sending a mobile phone text message with a request to participate, and making a telephone call to ask subjects to participate after a certain time interval. We obtained informed consent and conducted examinations at community centers or house visits. The follow-up involved administration of a questionnaire, a physical examination, 24-hour diet recall, and blood tests, the same items as in the baseline survey.

Of the 514 followed-up participants, after excluding 6 subjects whose blood $\mathrm{Hg}$ levels or liver function indices (AST, ALT, GGT) were not measured in the baseline or follow-up, 508 participants were included in the analysis (Supplemental Figure 1).

This study was conducted in accordance with the Declaration of Helsinki of the World Medical Association (http://www. wma.net) and approved by the institutional review board of Dankook University Hospital (DKUH 2010-04-0093, DKUH 2011-03-0086, DKUH 2014-02-016, DKUH 2015-01-006).

\section{Blood Mercury}

To analyze blood $\mathrm{Hg}$ levels, $3 \mathrm{~mL}$ of blood was collected in an ethylenediaminetetraacetic acid tube as part of the 20102011 baseline survey and the 2014-2015 follow-up survey. Whole blood was stored at $-80^{\circ} \mathrm{C}$ until analysis. The blood $\mathrm{Hg}$ analysis was performed using a MA-3000 direct $\mathrm{Hg}$ analyzer (Nippon Instrument Co., Tokyo, Japan). Quality control of the blood $\mathrm{Hg}$ analysis was performed intermittently using standard reference materials from the German external quality assessment scheme (Germany) and Bio-Rad (Bio-Rad Inc., Hercules, California, USA). The limit of detection was $0.20 \mu \mathrm{g} / \mathrm{L}$, and no samples had a $\mathrm{Hg}$ level below the limit of detection. 


\section{Liver Function Enzymes}

To analyze serum AST, ALT and GGT levels, $8 \mathrm{~mL}$ of blood was collected in an serum separator tube. The collected blood was stored at $-80^{\circ} \mathrm{C}$ until analysis. The liver enzymes were analyzed using a Hitachi 7600 DDP analyzer (Hitachi High-Technologies, Tokyo, Japan).

\section{Covariates}

Fish intake was measured by the 24-hour diet recall method in the baseline survey and at follow-up. The 24-hour diet recall was designed to record the diet of 2 non-consecutive days, and the average intake $(\mathrm{g} / \mathrm{kg} / \mathrm{d})$ was calculated for various food groups. Intake was classified into the first $(<0.20 \mathrm{~g} / \mathrm{kg} / \mathrm{d})$, second $(0.20-0.72 \mathrm{~g} / \mathrm{kg} / \mathrm{d})$, third $(0.73-1.45 \mathrm{~g} / \mathrm{kg} / \mathrm{d})$, and fourth quarters ( $\geq 1.46 \mathrm{~g} / \mathrm{kg} / \mathrm{d}$ ) of total fish consumption. In addition, data from the questionnaire regarding gender, age (years), residence (urban or rural area), income $(<100,100-200,200$ $300,300-400,400-600$, or $\geq 600 \times 10^{4}$ Korean won/mo), lifetime smoking (yes or no), frequency of alcohol consumption (none, less than once a month, about once a month, 2-4 times a month, 2-3 times a week, or $\geq 4$ times a week), and past medical history (yes or no) of hypertension (HTN), diabetes mellitus (DM), kidney disease, tuberculosis (TB), dyslipidemia, or hepatitis B were included as covariates. For the residence variable, we divided regions into 2 groups: urban (Seoul, Ulsan, Incheon, Daejeon, Gwangju, Daegu, and Busan) and rural (all others).

\section{Statistical Analysis}

The distribution of general characteristics, blood $\mathrm{Hg}$ levels, and liver enzyme levels was assessed by descriptive statistics such as frequency, proportion, arithmetic/geometric mean and standard deviation (SD), minimum, 25th percentile, median, 75th percentile, and maximum. Because the distributions of blood $\mathrm{Hg}$ and liver enzyme levels were right-skewed, logtransformed values were used to test the differences according to the subjects' characteristics, and the Student $t$-test and analysis of variance were used.

A generalized linear model (GLM) was used to analyze crosssectional associations between blood $\mathrm{Hg}$ and liver enzyme levels at baseline and follow-up. Nonlinear relationships were examined using a generalized additive mixed model (GAMM). In this model, the base- 2 log blood $\mathrm{Hg}$ level was given a cubic regression spline function. The population-averaged association over the period of the study between blood $\mathrm{Hg}$ and liver enzyme levels was analyzed using a generalized estimating equations (GEE) model considering repeated measures for the same individuals stratified by gender. In the GEE analysis, the interaction of blood $\mathrm{Hg}$ and the frequency of alcohol consumption in association with liver enzymes was evaluated.

In all analyses, natural log-transformed liver enzyme levels and base 2 log-transformed blood $\mathrm{Hg}$ levels were used as response and predictor variables, respectively. Survey wave, gender, age, income, fish consumption, smoking, frequency of alcohol consumption, and past medical history were considered as covariates in the regression models, and individuals were included in GAMM as random intercepts. Each variable corresponded to values measured at each survey wave in the GLM, and were considered to be time-varying covariates in the GAMM and GEE. The significance level for tests was 0.05 , and R version 3.3.3 (Comprehensive R Archive Network: http:// cran.r-project.org) was used.

\section{RESULTS}

In the baseline survey, the geometric mean (geometric SD) levels of blood $\mathrm{Hg}, \mathrm{ALT}, \mathrm{AST}$, and GGT in all participants were $4.33 \mu \mathrm{g} / \mathrm{L}$ (1.94 $\mu \mathrm{g} / \mathrm{L}), 21.2 \mathrm{IU} / \mathrm{L}$ (1.4 IU/L), $18.3 \mathrm{IU} / \mathrm{L}$ (1.7 IU/L), and $23.4 \mathrm{IU} / \mathrm{L}(2.0 \mathrm{IU} / \mathrm{L})$, respectively. Blood Hg levels were significantly higher in men than women, as age increased, in smokers than non-smokers, as fish intake increased, as the frequency of alcohol consumption increased, and in individuals with a history of HTN or TB. All 3 liver enzymes were significantly higher in men than women, as age increased, in smokers than non-smokers, as the frequency of alcohol consumption increased, and in those with a history of HTN. ALT and GGT were significantly higher in those with a history of DM, ALT was significantly higher in those with a history of TB, and AST and ALT were significantly higher in those with a history of hepatitis B than their respective counterparts (Table 1).

Compared to the baseline values, the follow-up concentrations of blood Hg and AST decreased, that of ALT increased, and that of GGT was similar $(p<0.001, p<0.001, p<0.001$, and $p=0.38$, respectively) (Table 2). Descriptive findings regarding the distribution of the change in levels of each enzyme, as well as $\mathrm{Hg}$ concentrations, from the baseline to follow-up are shown in Supplemental Table 1.

Significant positive associations were found between blood $\mathrm{Hg}$ and GGT at baseline and follow-up (in all participants and in women), but no significant associations with AST or ALT 
Table 1. Distribution of levels of blood Hg and liver enzymes according to the characteristics of study participants at baseline (2010-2011)

\begin{tabular}{|c|c|c|c|c|c|c|c|c|c|}
\hline & n (\%) & $\mathrm{Hg}(\mu \mathrm{g} / \mathrm{L})$ & $p$-value ${ }^{1}$ & AST (IU/L) & $p$-value ${ }^{1}$ & ALT (IU/L) & $p$-value ${ }^{1}$ & GGT (IU/L) & $p$-value ${ }^{1}$ \\
\hline Total & $508(100.0)$ & $4.33(1.94)$ & & $21.2(1.4)$ & & $18.3(1.7)$ & & $23.4(2.0)$ & \\
\hline \multicolumn{10}{|l|}{ Gender } \\
\hline Men & $211(41.5)$ & $5.71(1.94)$ & & $23.2(1.4)$ & & $22.6(1.6)$ & & $36.1(2.0)$ & \\
\hline Women & $297(58.5)$ & $3.55(1.80)$ & $<0.001$ & $19.8(1.4)$ & $<0.001$ & $15.7(1.6)$ & $<0.001$ & $17.2(1.7)$ & $<0.001$ \\
\hline \multicolumn{10}{|l|}{ Age at baseline (y) } \\
\hline$\leq 29$ & $53(10.4)$ & $2.87(1.70)$ & & $19.2(1.5)$ & & $15.1(2.1)$ & & $17.5(1.7)$ & \\
\hline $30-39$ & 73 (14.4) & $3.99(1.77)$ & & $18.3(1.3)$ & & $16.5(1.6)$ & & 20.4 (1.9) & \\
\hline $40-49$ & $113(22.2)$ & $4.57(2.06)$ & & $21.3(1.5)$ & & $19.3(1.7)$ & & $26.0(2.2)$ & \\
\hline $50-59$ & 135 (26.6) & $4.22(1.86)$ & & $21.8(1.4)$ & & $18.9(1.6)$ & & $22.3(1.9)$ & \\
\hline$\geq 60$ & 134 (26.4) & $5.20(1.95)$ & $<0.001$ & $23.1(1.3)$ & $<0.001$ & $19.3(1.5)$ & 0.008 & $27.1(2.0)$ & $<0.001$ \\
\hline \multicolumn{10}{|l|}{ Residence } \\
\hline Rural area & $305(60.0)$ & $4.49(1.89)$ & & $21.0(1.4)$ & & $18.5(1.7)$ & & $24.1(2.1)$ & \\
\hline Urban area & $203(40.0)$ & 4.09 (2.01) & 0.12 & $21.4(1.4)$ & 0.57 & $18.1(1.7)$ & 0.64 & 22.4 (1.9) & 0.24 \\
\hline \multicolumn{10}{|l|}{ Income $\left(10^{4} \mathrm{KRW} / \mathrm{mo}\right)$} \\
\hline$<100$ & $83(17.1)$ & $4.34(2.04)$ & & $22.0(1.4)$ & & $18.3(1.5)$ & & $25.5(2.0)$ & \\
\hline $100-200$ & $112(23.0)$ & $4.48(1.96)$ & & $22.2(1.4)$ & & 19.3 (1.8) & & $25.5(2.2)$ & \\
\hline $200-300$ & $140(28.8)$ & $4.32(1.82)$ & & $21.3(1.5)$ & & $17.9(1.7)$ & & $22.0(2.1)$ & \\
\hline $300-400$ & 77 (15.8) & $4.42(1.99)$ & & $20.6(1.3)$ & & $18.5(1.6)$ & & 24.4 (1.8) & \\
\hline $400-600$ & $55(11.3)$ & $3.84(1.94)$ & & $19.1(1.3)$ & & $17.0(1.7)$ & & $19.8(1.8)$ & \\
\hline$\geq 600$ & $19(3.9)$ & $6.06(2.10)$ & 0.23 & $20.4(1.5)$ & 0.14 & $20.7(1.9)$ & 0.60 & $24.4(2.1)$ & 0.19 \\
\hline \multicolumn{10}{|l|}{ History of smoking } \\
\hline No & $332(65.9)$ & $3.74(1.83)$ & & $20.4(1.4)$ & & $16.5(1.6)$ & & $18.6(1.7)$ & \\
\hline Yes & $172(34.1)$ & $5.76(1.96)$ & $<0.001$ & $22.8(1.5)$ & $<0.001$ & $22.3(1.6)$ & $<0.001$ & $36.2(2.1)$ & $<0.001$ \\
\hline \multicolumn{10}{|c|}{ Frequency of alcohol consumption } \\
\hline None & $124(24.6)$ & $3.90(1.95)$ & & $20.9(1.4)$ & & $17.9(1.6)$ & & $19.6(1.7)$ & \\
\hline$<1 /$ mo & $74(14.7)$ & $3.61(1.90)$ & & $19.7(1.4)$ & & $16.1(1.6)$ & & $17.6(1.7)$ & \\
\hline $1 / \mathrm{mo}$ & $68(13.5)$ & $4.41(1.74)$ & & $20.2(1.4)$ & & $18.0(1.7)$ & & $19.9(1.9)$ & \\
\hline 2-4 times/mo & $117(23.2)$ & $3.97(1.94)$ & & $19.7(1.3)$ & & $17.1(1.6)$ & & $21.6(1.8)$ & \\
\hline 2-3 times/wk & $74(14.7)$ & $5.29(1.86)$ & & $23.5(1.5)$ & & $21.0(1.8)$ & & $32.8(2.0)$ & \\
\hline 4+ times/wk & $48(9.5)$ & $6.75(1.89)$ & $<0.001$ & $26.2(1.5)$ & $<0.001$ & $23.0(1.6)$ & $<0.001$ & $51.9(2.5)$ & $<0.001$ \\
\hline \multicolumn{10}{|l|}{ Fish consumption $(\mathrm{g} / \mathrm{kg} / \mathrm{d})$} \\
\hline 1st quarter $(<0.20)$ & $117(23.1)$ & $3.93(1.91)$ & & $22.0(1.4)$ & & $19.7(1.7)$ & & $27.9(2.1)$ & \\
\hline 2nd quarter (0.20-0.72) & $139(27.4)$ & $3.90(1.95)$ & & $20.9(1.5)$ & & $17.5(1.7)$ & & $22.4(2.0)$ & \\
\hline 3rd quarter (0.73-1.45) & $124(24.5)$ & $4.14(1.95)$ & & $20.8(1.4)$ & & $17.5(1.7)$ & & $20.7(1.9)$ & \\
\hline 4th quarter ( $\geq 1.46$ ) & $127(25.0)$ & $5.55(1.83)$ & $<0.001$ & $21.1(1.3)$ & 0.61 & $18.9(1.6)$ & 0.18 & $23.8(2.0)$ & 0.007 \\
\hline \multicolumn{10}{|l|}{ Past medical history } \\
\hline \multicolumn{10}{|l|}{ Hypertension } \\
\hline No & $362(73.6)$ & $4.07(1.91)$ & & $20.5(1.4)$ & & $17.4(1.7)$ & & $21.3(1.9)$ & \\
\hline Yes & $130(26.4)$ & $5.13(2.00)$ & 0.001 & $22.7(1.4)$ & 0.003 & $20.7(1.6)$ & 0.001 & $29.4(2.1)$ & $<0.001$ \\
\hline \multicolumn{10}{|l|}{ Diabetes mellitus } \\
\hline No & 433 (88.5) & $4.34(1.97)$ & & $20.8(1.4)$ & & $17.8(1.7)$ & & $22.6(2.0)$ & \\
\hline Yes & $56(11.5)$ & $4.27(1.82)$ & 0.86 & $22.6(1.4)$ & 0.08 & $21.7(1.7)$ & 0.007 & $29.0(2.0)$ & 0.01 \\
\hline \multicolumn{10}{|l|}{ Kidney disease } \\
\hline No & $455(94.6)$ & $4.36(1.97)$ & & $21.0(1.4)$ & & $18.4(1.7)$ & & $23.5(2.0)$ & \\
\hline Yes & $26(5.4)$ & $4.33(1.80)$ & 0.96 & $20.5(1.2)$ & 0.70 & $15.7(1.3)$ & 0.12 & $19.4(1.7)$ & 0.18 \\
\hline \multicolumn{10}{|l|}{ Tuberculosis } \\
\hline No & $453(94.4)$ & $4.26(1.95)$ & & $20.9(1.4)$ & & $17.9(1.7)$ & & $23.0(2.0)$ & \\
\hline Yes & $27(5.6)$ & $6.15(1.94)$ & 0.006 & $23.4(1.4)$ & 0.08 & $24.1(1.7)$ & 0.003 & $28.6(2.0)$ & 0.11 \\
\hline \multicolumn{10}{|l|}{ Dyslipidemia } \\
\hline No & 448 (92.8) & $4.34(1.96)$ & & $21.0(1.4)$ & & $18.2(1.7)$ & & $23.2(2.0)$ & \\
\hline Yes & $35(7.2)$ & $4.35(1.82)$ & 0.99 & $21.0(1.3)$ & 0.95 & $19.3(1.7)$ & 0.53 & $24.3(1.9)$ & 0.72 \\
\hline \multicolumn{10}{|l|}{ Hepatitis B } \\
\hline No & 439 (92.0) & $4.38(1.93)$ & & $20.8(1.4)$ & & $18.0(1.7)$ & & $23.2(2.0)$ & \\
\hline Yes & $38(8.0)$ & $4.44(2.07)$ & 0.91 & $23.1(1.4)$ & 0.06 & $21.6(1.6)$ & 0.03 & $22.7(1.8)$ & 0.85 \\
\hline
\end{tabular}

Values are presented as geometric mean (geometric standard deviation).

$\mathrm{Hg}$, mercury; AST, aspartate aminotransferase; ALT, alanine transaminase; GGT, gamma-glutamyltransferase; KRW, Korean won.

${ }^{1} p$-values were calculated using the $t$-test or analysis of variance with natural log-transformed values of $\mathrm{Hg}, A S T$, ALT, and GGT. 
Table 2. Distribution of levels of blood Hg and liver enzymes at baseline and follow-up

\begin{tabular}{|c|c|c|c|c|c|c|c|c|c|}
\hline $\begin{array}{l}\text { Survey wave } \\
\text { (periods) }\end{array}$ & $\begin{array}{l}\text { Blood } \mathrm{Hg} \text { or } \\
\text { liver enzymes }\end{array}$ & Mean (SD) & gMean (gSD) & Min & 1st 0 & Median & 3rd 0 & Max & $p$-value ${ }^{1}$ \\
\hline \multirow{4}{*}{$\begin{array}{l}\text { Baseline } \\
\text { (2010-2011) }\end{array}$} & $\mathrm{Hg}(\mu \mathrm{g} / \mathrm{L})$ & $5.44(4.40)$ & $4.33(1.94)$ & 0.46 & 2.90 & 4.22 & 6.54 & 41.95 & \\
\hline & AST (IU/L) & $22.8(12.9)$ & $21.2(1.4)$ & 10.0 & 17.0 & 20.0 & 24.0 & 187.0 & \\
\hline & ALT (IU/L) & $21.3(15.2)$ & $18.3(1.7)$ & 5.0 & 13.0 & 17.0 & 24.0 & 153.0 & \\
\hline & GGT (IU/L) & $31.9(37.8)$ & $23.4(2.0)$ & 7.0 & 14.0 & 20.0 & 36.0 & 473.0 & \\
\hline \multirow{4}{*}{$\begin{array}{l}\text { Follow-up } \\
\text { (2014-2015) }\end{array}$} & $\mathrm{Hg}(\mu \mathrm{g} / \mathrm{L})$ & $4.08(3.44)$ & $3.18(2.00)$ & 0.31 & 2.02 & 3.05 & 5.01 & 26.90 & $<0.001$ \\
\hline & AST (IU/L) & $21.8(16.2)$ & $18.3(1.7)$ & 2.5 & 13.0 & 17.0 & 25.0 & 169.0 & $<0.001$ \\
\hline & ALT (IU/L) & $22.5(10.8)$ & $20.9(1.4)$ & 9.0 & 16.0 & 20.0 & 25.0 & 93.0 & $<0.001$ \\
\hline & GGT (IU/L) & 32.7 (42.2) & $23.8(2.0)$ & 6.0 & 14.0 & 21.0 & 36.0 & 589.0 & 0.38 \\
\hline
\end{tabular}

Hg, mercury; SD, standard deviation; gMean, geometric mean; gSD, geometric standard deviation; Min, minimum; 1st 0, 1st quartile; 3rd 0, 3rd quartile; Max maximum; AST, aspartate aminotransferase; ALT, alanine transaminase; GGT, gamma-glutamyltransferase.

${ }^{1} p$-values were calculated using the paired $t$-test for differences in the geometric mean between survey waves.

Table 3. Generalized linear model' of associations between blood Hg levels and liver enzymes at baseline (2010-2011) and follow-up (2014-2015) by gender

\begin{tabular}{|c|c|c|c|c|c|c|c|}
\hline & \multirow[b]{2}{*}{ Survey wave } & \multicolumn{2}{|c|}{ AST } & \multicolumn{2}{|c|}{ ALT } & \multicolumn{2}{|c|}{ GGT } \\
\hline & & $\begin{array}{c}\% \text { change } \\
(95 \% \text { CI })^{2}\end{array}$ & $\begin{array}{c}p \text { for } \\
\text { interaction }\end{array}$ & $\begin{array}{l}\text { \% change } \\
(95 \% \text { CI })^{2}\end{array}$ & $\begin{array}{c}p \text { for } \\
\text { interaction }\end{array}$ & $\begin{array}{l}\text { \% change } \\
(95 \% \mathrm{Cl})^{2}\end{array}$ & $\begin{array}{c}p \text { for } \\
\text { interaction }^{3}\end{array}$ \\
\hline \multirow[t]{2}{*}{ All } & Baseline & $-1.2(-4.7,2.5)$ & & $2.2(-3.3,7.9)$ & & $8.3(1.8,15.2)^{*}$ & \\
\hline & Follow-up & $3.6(-2.2,9.8)$ & 0.03 & $-0.6(-4.2,3.1)$ & 0.003 & $10.3(3.5,17.6)^{*}$ & 0.60 \\
\hline \multirow[t]{2}{*}{ Men } & Baseline & $-2.5(-7.9,3.3)$ & & $0.7(-7.3,9.3)$ & & $6.1(-4.8,18.2)$ & \\
\hline & Follow-up & $0.9(-7.0,9.4)$ & 0.69 & $-3.1(-8.6,2.8)$ & 0.16 & $9.4(-2.0,22.2)$ & 0.70 \\
\hline \multirow[t]{2}{*}{ Womene } & Baseline & $-0.5(-5.3,4.6)$ & & $3.0(-4.4,11.0)$ & & $9.7(1.7,18.2)^{*}$ & \\
\hline & Follow-up & $5.6(-2.8,14.7)$ & 0.12 & $2.1(-2.9,7.3)$ & 0.54 & $12.3(3.5,21.8)^{*}$ & 0.61 \\
\hline
\end{tabular}

Hg, mercury; AST, aspartate aminotransferase; ALT, alanine transaminase; GGT, gamma-glutamyltransferase.

'Generalized linear model adjusted for gender (in all), age, income, fish consumption, smoking, frequency of alcohol consumption, and past medical history of hypertension, diabetes mellitus, tuberculosis, or hepatitis B measured at each period.

$2 \%$ change of liver enzyme per doubling of blood $\mathrm{Hg}$ levels.

${ }^{3}$ Interactions between blood $\mathrm{Hg}$ levels and survey wave in association with liver function indices were evaluated by the interaction term in the generalized estimating equation model.

${ }^{*} p<0.05$.

were observed. Although the association of blood $\mathrm{Hg}$ with AST and ALT in all participants showed a significant difference between the 2 survey waves, there was no significant difference after stratification by gender (Table 3). There was no statistically significant association between blood $\mathrm{Hg}$ levels at baseline or changes in blood $\mathrm{Hg}$ and changes in liver enzyme levels between surveys (Supplemental Table 2).

The relationships between blood $\mathrm{Hg}$ levels and liver enzyme levels are illustrated in Figure 1. In men, AST and ALT showed little change as blood $\mathrm{Hg}$ levels increased, and GGT showed an increase with a downward curvature. In women, AST, ALT, and GGT showed an increase with an upward curvature.

The associations between blood Hg and AST or ALT, when adjusted for other covariates and individual correlations in re- peated measurements, were not significant in either gender (Table 4). GGT showed a significant association with blood Hg levels in women and borderline significance in men. The association between blood $\mathrm{Hg}$ and AST was significantly different by gender ( $p$ for interaction $=0.02$ ).

In women who consumed alcohol $\geq 2-3$ times per week, all 3 liver enzymes showed significant positive associations with blood $\mathrm{Hg}$ levels, and the effects of blood $\mathrm{Hg}$ and frequency of alcohol consumption on GGT showed a significant synergistic interaction ( $p$ for interaction $=0.008$ ) (Table 4). The frequency and amount of alcohol consumption were strongly correlated (Supplemental Table 3), and the results were similar to those of drinking frequency when the analysis was repeated using the amount of alcohol consumed (Supplemental Table 4). 

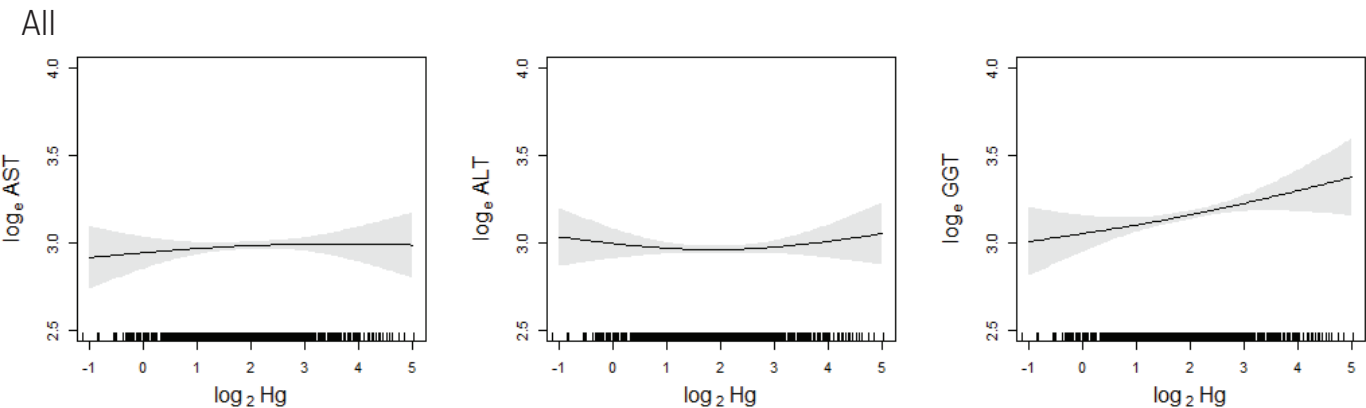

Men
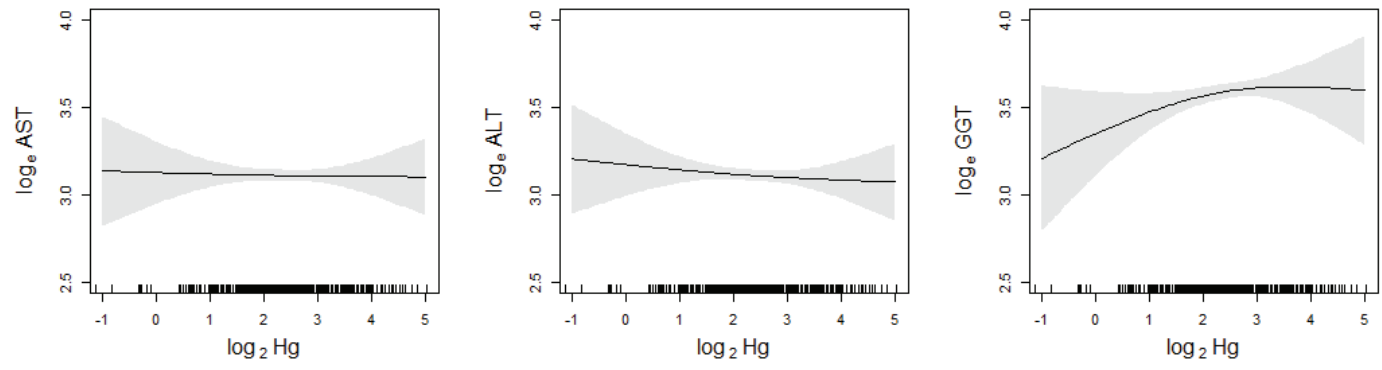

Women
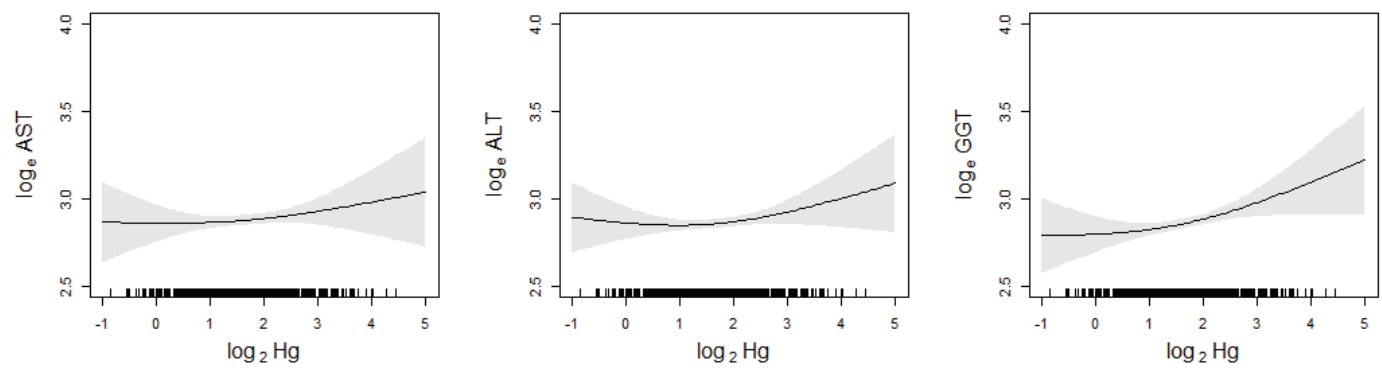

Figure 1. Relationship between blood levels of $\mathrm{Hg}$ and liver enzymes in adults. The smoothing line is fitted by using the generalized additive model (GAM), and the gray shade is the $95 \%$ confidence bands for smooths. GAM used both baseline and followup data, and nonlinear relationship was evaluated using cubic regression spline function to base-2 log $\mathrm{Hg}$, adjusted for gender (in all), age, income, fish consumption, smoking, drinking alcohol, past medical history of hypertension, diabetes mellitus, tuberculosis, hepatitis B, and survey wave with a random intercept for individuals. In each model, age, income, survey wave, fish consumption, smoking and drinking alcohol frequency as well as blood $\mathrm{Hg}$ and liver enzymes are considered as time-varying covariates. Hg, mercury; AST, aspartate aminotransferases; ALT, alanine transaminase; GGT, gamma-glutamyltransferase.

\section{DISCUSSION}

In this study, higher blood Hg levels were associated with higher serum GGT levels in men and women. Especially in women who drank alcohol frequently, higher blood $\mathrm{Hg}$ levels were significantly associated with elevated AST and ALT levels, as well as GGT, and a significant synergistic effect between $\mathrm{Hg}$ and alcohol consumption on liver enzyme levels was observed.

The geometric mean values of the blood $\mathrm{Hg}$ at baseline and follow-up were $4.33 \mu \mathrm{g} / \mathrm{L}$ and $3.18 \mu \mathrm{g} / \mathrm{L}$, respectively. In the 2012 and 2015 KoNEHS data, the geometric mean levels of blood $\mathrm{Hg}$ were reported as $3.08 \mu \mathrm{g} / \mathrm{L}$ and $3.11 \mu \mathrm{g} / \mathrm{L}$, respectively, and Seo et al. [5] and Lee et al. [12] reported values of 3.08 $\mu \mathrm{g} / \mathrm{L}$ and $3.99 \mu \mathrm{g} / \mathrm{L}$, respectively. Compared to those previous Korean studies, the baseline concentration in the present study was higher and the concentration at follow-up was similar.

In previous epidemiological studies, blood Hg showed a significant positive association with ALT in NHANES 2003-2004 [11], and with AST and ALT in KNHANES 2008-2012 [12]. A recent study [13] reported significantly higher AST levels in the highest quarter of blood $\mathrm{Hg}$ levels than in the lowest quarter, and the odds of high ALT levels ( $>35 \mathrm{IU} / \mathrm{L}$ ) were 3.10 times 
Table 4. Generalized estimating equation model of associations between blood Hg levels and liver enzymes from baseline (2010-2011) to follow-up (2014-2015), stratified by gender

\begin{tabular}{|c|c|c|c|c|c|c|c|}
\hline & & \multicolumn{2}{|c|}{ AST } & \multicolumn{2}{|c|}{ ALT } & \multicolumn{2}{|c|}{ GGT } \\
\hline & & $\begin{array}{l}\% \text { change } \\
(95 \% \text { CI })^{1}\end{array}$ & $\begin{array}{c}p \text { for } \\
\text { interaction }\end{array}$ & $\begin{array}{l}\% \text { change } \\
(95 \% \text { CI })^{1}\end{array}$ & $\begin{array}{c}p \text { for } \\
\text { interaction }\end{array}$ & $\begin{array}{l}\% \text { change } \\
(95 \% \text { CI })^{1}\end{array}$ & $\begin{array}{c}p \text { for } \\
\text { interaction }\end{array}$ \\
\hline \multirow[t]{7}{*}{ Men } & Crude & $1.8(-2.4,6.1)$ & & $0.6(-3.8,5.3)$ & & $12.7(3.2,23.0)^{*}$ & \\
\hline & Model 1 & $1.6(-2.7,6.0)$ & & $-0.1(-4.9,4.8)$ & & $10.4(-0.1,22.1)^{\dagger}$ & \\
\hline & Model 2 & $1.3(-3.3,6.0)$ & & $-0.8(-5.5,4.1)$ & & $7.5(-1.8,17.7)$ & \\
\hline & Model 3 & $-0.1(-4.7,4.7)$ & & $-1.2(-5.6,3.4)$ & & $8.1(-0.5,17.4)^{\dagger}$ & \\
\hline & Alcohol consumption fr & & & & & & \\
\hline & $\leq 2-4$ times $/ \mathrm{mo}$ & $3.6(-2.3,9.8)$ & & $2.9(-2.5,8.6)$ & & $7.6(-2.0,18.2)$ & \\
\hline & $\geq 2-3$ times/wk & $-1.7(-9.0,6.2)$ & 0.88 & $-2.7(-10.5,5.7)$ & 0.31 & $13.5(-2.0,31.4)^{\dagger}$ & 0.39 \\
\hline \multirow[t]{7}{*}{ Women } & Crude & $6.9(2.8,11.2)^{*}$ & & $0.9(-2.9,4.8)$ & & $7.0(1.1,13.3)^{*}$ & \\
\hline & Model 1 & $2.1(-1.9,6.2)$ & & $1.8(-2.2,6.0)$ & & $8.1(1.4,15.2)^{*}$ & \\
\hline & Model 2 & $2.2(-1.7,6.2)$ & & $1.5(-2.4,5.6)$ & & $9.1(2.3,16.3)^{*}$ & \\
\hline & Model 3 & $3.2(-1.1,7.6)$ & & $2.4(-1.7,6.6)$ & & $11.0(4.5,18.0)^{*}$ & \\
\hline & Alcohol consumption $\mathrm{fr}$ & & & & & & \\
\hline & $\leq 2-4$ times/mo & $2.5(-2.2,7.4)$ & & $2.0(-2.4,6.7)$ & & $7.8(1.2,14.7)^{*}$ & \\
\hline & $\geq 2-3$ times/wk & $10.6(4.2,17.5)^{*}$ & 0.22 & $7.7(1.1,14.7)^{*}$ & 0.37 & $37.5(15.2,64.3)^{*}$ & 0.008 \\
\hline \multicolumn{3}{|c|}{$p$ for interaction between genders ${ }^{4}$} & 0.02 & & 0.53 & & 0.82 \\
\hline
\end{tabular}

Model 1 included age, income, and study period in the crude model; Model 2 included fish consumption, smoking, and frequency of alcohol consumption in addition to model 1; Model 3 included past medical history of hypertension, diabetes mellitus, tuberculosis, or hepatitis B in addition to model 2. In each model, age, income, period, fish consumption, smoking, and frequency of alcohol consumption, as well as blood $\mathrm{Hg}$ and liver enzyme levels, were considered to be timevarying covariates.

$\mathrm{Hg}$, mercury; $\mathrm{Cl}$, confidence interval; AST, aspartate aminotransferase; ALT, alanine transaminase; GGT, gamma-glutamyltransferase.

$1 \%$ change of liver enzyme per doubling of blood $\mathrm{Hg}$ level.

${ }^{2}$ The multiplicative interaction between blood Hg levels and frequency of alcohol consumption in association with liver enzymes was evaluated by the interaction term in the corresponding model.

${ }^{3}$ After stratification by frequency of alcohol consumption, the same covariates as model 3 were included.

${ }^{4}$ The multiplicative interaction between blood $\mathrm{Hg}$ levels and gender in association with liver enzymes was evaluated by the interaction term in the corresponding model (model 3).

${ }^{\dagger} p<0.1,{ }^{*} p<0.05$.

higher in the highest quarter of blood $\mathrm{Hg}$ levels than in the lowest quarter in a repeated-measures study of Koreans over 60 years old. However, other studies have reported no association $[9,10]$, and conflicting results have been reported depending on whether liver dysfunction was defined as a continuous or dichotomous variable within the same study [13]. Significantly higher GGT levels were found in the secondhighest and highest quarters of blood $\mathrm{Hg}$ levels than in the lowest quarter [13], and the odds of high GGT ( $>47$ IU/L for men and $>21 \mathrm{IU} / \mathrm{L}$ for women) were 2.59 times higher for men and 2.03 times higher for women in the highest quarter of blood $\mathrm{Hg}$ levels than in the lowest quarter [14]. The differences in results among studies may be explained by various factors, such as differences in the adjusted confounding variables, study design, sample size, and whether effect modifiers such as alcohol consumption and gender were considered. In the present study, an interaction between blood $\mathrm{Hg}$ levels and alcohol consumption was observed for GGT in women, which was consistent with previous results. This may have been because GGT is a more sensitive biomarker for alcohol consumption than AST or ALT [13].

The biological mechanism of associations between $\mathrm{Hg}$ exposure and liver dysfunction is mainly explained by oxidative stress, cell death, and impairment of metabolism. In a study using NHANES 1988-1994 data, negative associations of GGT with antioxidants including a-carotene, h-carotene, h-cryptoxanthin, zeaxanthin/lutein, lycopene, and vitamin C were reported, suggesting that GGT may be considered an early oxidative stress marker [16]. In an animal study of male rats exposed to Hg, AST, ALT, and GGT were significantly elevated, and marked damage or necrotic changes were observed in most of the liver tissue samples upon a histological examina- 
tion [17]. Degenerative changes and large lysed areas in liver parenchyma in $\mathrm{Hg}$-exposed zebrafish have been observed [18]. In addition, $\mathrm{Hg}$ exposure in zebrafish induced deregulation of oxidative stress, intrinsic apoptotic pathways, and nuclear receptor and kinase activity [19], suggesting that gluconeogenesis and adipogenesis occur in these processes and that hepatotoxicity occurs through cell death, mitochondrial dysfunction, endocrine disruption, and metabolic disorders. Koenig and Seneff [20] proposed that GGT, an indicator of alcohol-related liver disease, is an important biomarker of cellular antioxidant inadequacy. Therefore, the results of the present study that GGT was susceptible to elevated blood Hg levels, mediated through an interaction with alcohol consumption, imply that $\mathrm{Hg}$ may induce hepatotoxicity through oxidative stress.

The present study has several strengths. First, we considered fish consumption as a potential confounder when examining associations between blood $\mathrm{Hg}$ levels and liver function. Fish is a major source of $\mathrm{Hg}$, and $80-90 \%$ of the organic $\mathrm{Hg}$ in the human body comes from fish and shellfish intake [21]. Because methylmercury is highly lipophilic and bioaccumulative, methylmercury exposure occurs mostly via food intake, such as fish consumption. Fish consumption increases total blood $\mathrm{Hg}$, while the antioxidant effects of fish oil and nutrients may offset the harmful effect of $\mathrm{Hg}$ on liver enzymes. Most previous studies have not considered fish consumption $[13,14]$. Second, we examined the possibility of a nonlinear association between $\mathrm{Hg}$ levels and liver enzyme levels. Most previous epidemiological studies have examined linear relationships or $\mathrm{Hg}$ levels divided into quantiles, which could lead to biased results if these variables have a nonlinear relationship. In the present study, we did not find evidence of a nonlinear association between $\mathrm{Hg}$ levels and liver function, although further studies are warranted to replicate our findings. Third, we analyzed the data with consideration of the repeatedly measured and longitudinal structure of the data, whereas most previous studies on the associations between $\mathrm{Hg}$ and liver enzymes were purely cross-sectional.

Nonetheless, this study has some limitations. First, we did not have information on organic $\mathrm{Hg}$ per se; instead, we measured the total $\mathrm{Hg}$ concentration. However, it is known that organic $\mathrm{Hg}$ accounts for most of the $\mathrm{Hg}$ content in the human body [21]. Specifically, methylmercury is known to contribute to about $90 \%$ of the total blood $\mathrm{Hg}$ concentration when the total $\mathrm{Hg}$ level is about $4 \mu \mathrm{g} / \mathrm{L}$ or more, and the total $\mathrm{Hg}$ in the general population is known to reflect organic $\mathrm{Hg}$ exposure unless individuals are exposed to high concentrations of inorganic $\mathrm{Hg}$ [22]. Therefore, in the present study, the analysis of total blood $\mathrm{Hg}$ could also be interpreted meaningfully as an analysis of organic $\mathrm{Hg}$ to some extent. Second, fish consumption was measured by the 24-hour diet recall method. This method was based on 2 non-consecutive days of diet recall, and the average intake $(\mathrm{g} / \mathrm{kg} / \mathrm{d})$ was calculated; this method may have introduced uncertainty in measurements of fish intake. Third, the frequency of alcohol consumption for the past year was measured by the questionnaire, whereas information on alcohol consumption the day before the test was not obtained, although this could have affected liver enzyme levels. However, because the introductory brochure provided to the enrollees contained information on drinking restrictions before the test, this impact should have been minimal.

In conclusion, total blood $\mathrm{Hg}$ exposure was associated with an increase in liver enzymes, particularly in women heavy drinkers. Women may be more sensitive to the hepatotoxic effects of $\mathrm{Hg}$, and $\mathrm{Hg}$ exposure showed a synergistic effect on liver damage with a high frequency of alcohol consumption.

\section{ACKNOWLEDGEMENTS}

This study was supported by the Korean Ministry of Food and Drug Safety (14162MFDS655). The authors thank Ms. Soojung Kim for her enthusiastic efforts to manage the project and to collect data, and all the participants for their valuable contributions.

\section{CONFLICT OF INTEREST}

The authors have no conflicts of interest associated with the material presented in this paper.

\section{ORCID}

Jonghyuk Choi https://orcid.org/0000-0002-8661-493X

Sanghyuk Bae https://orcid.org/0000-0002-4995-6543

Hyungryul Lim https://orcid.org/0000-0002-3371-0557

Ji-Ae Lim https://orcid.org/0000-0003-0623-2446

Yong-Han Lee https://orcid.org/0000-0002-4130-8445

Mina Ha https://orcid.org/0000-0003-1011-9446

Ho-Jang Kwon https://orcid.org/0000-0003-3029-5674 


\section{REFERENCES}

1. Genchi G, Sinicropi MS, Carocci A, Lauria G, Catalano A. Mercury exposure and heart diseases. Int J Environ Res Public Health 2017;14(1):E74.

2. World Health Organization. Exposure to mercury: a major public health concern, preventing disease through healthy environment. Geneva: World Health Organization; 2007, p.1.

3. Yaginuma-Sakurai K, Murata K, Iwai-Shimada M, Nakai K, Kurokawa N, Tatsuta N, et al. Hair-to-blood ratio and biological half-life of mercury: experimental study of methylmercury exposure through fish consumption in humans. J Toxicol Sci 2012;37(1):123-130.

4. Awata $\mathrm{H}$, Linder S, Mitchell LE, Delclos GL. Biomarker levels of toxic metals among Asian populations in the United States: NHANES 2011-2012. Environ Health Perspect 2017;125(3): 306-313.

5. Seo JW, Kim BG, Kim YM, Kim RB, Chung JY, Lee KM, et al. Trend of blood lead, mercury, and cadmium levels in Korean population: data analysis of the Korea National Health and Nutrition Examination Survey. Environ Monit Assess 2015;187 (3):146.

6. Harada M. Minamata disease: methylmercury poisoning in Japan caused by environmental pollution. Crit Rev Toxicol 1995;25(1):1-24

7. Mahaffey KR. Mercury exposure: medical and public health issues. Trans Am Clin Climatol Assoc 2005;116:127-154.

8. Fernandes Azevedo B, Barros Furieri L, Peçanha FM, Wiggers GA, Frizera Vassallo P, Ronacher Simões M, et al. Toxic effects of mercury on the cardiovascular and central nervous systems. J Biomed Biotechnol 2012;2012:949048.

9. Futatsuka M, Kitano T, Nagano M, Inaoka T, Arimatsu Y, Ueno T, et al. An epidemiological study with risk analysis of liver diseases in the general population living in a methyl mercury polluted area. J Epidemiol Community Health 1992;46(3):237240.

10. Poursafa P, Ataee E, Motlagh ME, Ardalan G, Tajadini MH, Yazdi $\mathrm{M}$, et al. Association of serum lead and mercury level with cardiometabolic risk factors and liver enzymes in a nationally representative sample of adolescents: the CASPIAN-III study. Environ Sci Pollut Res Int 2014;21(23):13496-13502.

11. Cave M, Appana S, Patel M, Falkner KC, McClain CJ, Brock G. Polychlorinated biphenyls, lead, and mercury are associated with liver disease in American adults: NHANES 2003-2004. En- viron Health Perspect 2010;118(12):1735-1742.

12. Lee H, Kim Y, Sim CS, Ham JO, Kim NS, Lee BK. Associations between blood mercury levels and subclinical changes in liver enzymes among South Korean general adults: analysis of 2008-2012 Korean National Health and Nutrition Examination Survey data. Environ Res 2014;130:14-19.

13. Lee MR, Lim YH, Lee BE, Hong YC. Blood mercury concentrations are associated with decline in liver function in an elderly population: a panel study. Environ Health 2017;16(1):17.

14. Seo MS, Lee HR, Shim JY, Kang HT, Lee YJ. Relationship between blood mercury concentrations and serum $\gamma$-glutamyltranspeptidase level in Korean adults using data from the 2010 Korean National Health and Nutrition Examination Survey. Clin Chim Acta 2014;430:160-163.

15. Lim JA, Kwon HJ, Ha M, Kim H, Oh SY, Kim JS, et al. Korean research project on the integrated exposure assessment of hazardous substances for food safety. Environ Health Toxicol 2015;30:e2015004.

16. Lim JS, Yang JH, Chun BY, Kam S, Jacobs DR Jr, Lee DH. Is serum gamma-glutamyltransferase inversely associated with serum antioxidants as a marker of oxidative stress? Free Radic Biol Med 2004;37(7):1018-1023.

17. Wadaan MA. Effects of mercury exposure on blood chemistry and liver histopathology of male rats. J Pharmacol Toxicol 2009;4(3):126-131.

18. Macirella R, Guardia A, Pellegrino D, Bernabò I, Tronci V, Ebbesson LO, et al. Effects of two sublethal concentrations of mercury chloride on the morphology and metallothionein activity in the liver of zebrafish (Danio rerio). Int J Mol Sci 2016;17(3):361.

19. Ung CY, Lam SH, Hlaing MM, Winata CL, Korzh S, Mathavan S, et al. Mercury-induced hepatotoxicity in zebrafish: in vivo mechanistic insights from transcriptome analysis, phenotype anchoring and targeted gene expression validation. BMC Genomics 2010;11:212.

20. Koenig G, Seneff S. Gamma-glutamyltransferase: a predictive biomarker of cellular antioxidant inadequacy and disease risk. Dis Markers 2015;2015:818570.

21. Hong YS, Kim YM, Lee KE. Methylmercury exposure and health effects. J Prev Med Public Health 2012;45(6):353-363.

22. Mahaffey KR, Clickner RP, Bodurow CC. Blood organic mercury and dietary mercury intake: National Health and Nutrition Examination Survey, 1999 and 2000. Environ Health Perspect 2004;112(5):562-570. 